\title{
Phenotypes Conferred by Wheat Multiple Pathogen Resistance Locus, Sr2, Include Cell Death in Response to Biotic and Abiotic Stresses
}

\author{
Linda Tabe, ${ }^{1}$ Sharon Samuel, ${ }^{2}$ Matthew Dunn, ${ }^{3}$ Rosemary White, ${ }^{1}$ Rohit Mago, ${ }^{1}$ Gonzalo Estavillo, ${ }^{1,4}$ \\ and Wolfgang Spielmeyer ${ }^{1, \dagger}$ \\ ${ }^{1}$ Agriculture and Food, Commonwealth Scientific and Industrial Research Organisation, Canberra, Australian Capital Territory 2601, Australia \\ ${ }^{2}$ University of Queensland, St. Lucia, Queensland 4072, Australia \\ ${ }^{3}$ Research School of Biological Sciences, Australian National University, Canberra, Australian Capital Territory 2601, Australia \\ ${ }^{4}$ Australian Research Council Centre of Excellence in Plant Energy Biology, Research School of Biology, Australian National University, \\ Acton, Australian Capital Territory 2601, Australia \\ Accepted for publication 11 June 2019.
}

\begin{abstract}
The wheat $S r 2$ locus confers partial resistance to four biotrophic pathogens: wheat stem rust (Puccinia graminis f. sp. tritici), leaf rust (P. triticina), stripe rust (P. striiformis f. sp. tritici), and powdery mildew (Blumeria graminis f. sp. tritici). In addition, $S r 2$ is linked with a brown coloration of ears and stems, termed pseudo-black chaff (PBC). PBC, initially believed to be elicited by stem rust infection, was subsequently recognized to occur in the absence of pathogen infection. The current study demonstrates that the resistance response to stem rust is associated with the death of photosynthetic cells around rust infection sites in the inoculated

leaf sheath. Similarly, $S r 2$-dependent resistance to powdery mildew was associated with the death of leaf mesophyll cells around mildew infection sites. We demonstrate that PBC occurring in the absence of pathogen inoculation also corresponds with death and the collapse of photosynthetic cells in the affected parts of stems and ears. In addition, Sr2-dependent necrosis was inducible in leaves by application of petroleum jelly or by heat treatments. Thus, $\mathrm{Sr} 2$ was found to be associated with cell death, which could be triggered by either biotic or abiotic stresses. Our results suggest a role for the $\mathrm{Sr} 2$ locus in controlling cell death in response to stress.
\end{abstract}

Rapidly evolving pathogens constitute a recurrent threat to widely used, highly effective, NOD-like receptor (NLR) plant disease resistance genes. For this reason, disease resistance genes with partial efficacy, broad specificity, and proven durability have received attention in wheat breeding programs as adjuncts to the NLR-type resistance genes. A number of the broad-range wheat disease resistance genes are effective only in reproductive-stage plants and are referred to as adult plant resistance (APR) genes. They generally afford only weak resistance, usually to all known races of a pathogen or to more than one pathogen species (Lagudah 2011). Understanding of the nature and mode of action of the NLR genes that confer effector-triggered immunity has advanced rapidly in recent years (reviewed by Zhang et al. 2017). In contrast, characterization of the wheat APR genes is only beginning, with understanding of the functions of these proteins in plant defense hampered by their structural diversity (Ellis et al. 2014; Fu et al. 2009; Krattinger et al. 2009; Moore et al. 2015). This study investigates cellular aspects of the mode of action of the wheat multipathogen APR locus, Sr2.

${ }^{\dagger}$ Corresponding author: W. Spielmeyer; wolfgang.spielmeyer@csiro.au

Current address of M. Dunn: Australian National Centre for the Public Awareness of Science, Australian National University, Canberra, Australian Capital Territory 2601, Australia.

Funding: This project was supported by the Grains Research Development Corporation.

*The $e$-Xtra logo stands for "electronic extra" and indicates that one supplementary figure is published online.

The author(s) declare no conflict of interest.

This article is in the public domain and not copyrightable. It may be freely reprinted with customary crediting of the source. The American Phytopathological Society, 2019.
$\mathrm{Sr} 2$ is one of few APR genes cataloged as conferring resistance to wheat stem rust (Puccinia graminis f. sp. tritici; Singh et al. 2011a). The $S r 2$ locus was introgressed from Yaroslav emmer wheat into hexaploid wheat in the 1920s (McFadden 1930), as part of an effort to combat damaging stem rust epidemics in the United States. The resulting variety, Hope, and its derivatives were used extensively as sources of stem rust resistance in North America and in the Green Revolution semidwarf wheat varieties bred for use in South America, Asia, and Africa (Rajaram et al. 1988). Sr2, along with three subsequently genetically defined resistance genes, provided highly effective resistance to stem rust in Hope. Eventual erosion of the resistance provided by this complex of genes in Hope was interpreted as defeat of some race-specific resistance genes by new P. graminis f. sp. tritici variants (e.g., by race 15B in 1950; Stakman and Rodenhiser 1959). It is believed that the partial resistance supplied by $S r 2$ alone has been durable for nearly 100 years, and it remains a key component of breeding strategies for durable resistance to wheat stem rust, including the newly emerged $U g 99$ suite of races (Ellis et al. 2014; Singh et al. 2011b).

The phenotype conferred by the $S r 2$ locus is complex. $S r 2$ stem rust resistance is partial, race nonspecific, and most reliably scored after anthesis (Sunderwirth and Roelfs 1980). In contrast, Lr27 specificity, which maps to the $S r 2$ locus, confers race-specific resistance to wheat leaf rust ( $P$. triticina) at all plant growth stages in partnership with the complementary gene Lr31 on chromosome 4B (Singh and McIntosh 1984a, b). Yr30, a minor quantitative trait locus for APR to stripe rust (P. striiformis f. sp. tritici), has also been mapped to the $S r 2$ locus (Suenaga et al. 2003; Yang et al. 2013). In addition, we reported linkage of $\mathrm{Sr} 2$ with moderate resistance to wheat powdery mildew (Blumeria graminis f. sp. tritici) in a mapping family in the Chinese Spring (CS) genetic background (Mago et al. 2011b). Thus, the Sr2 locus confers some level of resistance to four biotrophic fungal pathogens of wheat.

Expression of $\mathrm{Sr} 2$ stem rust resistance is often associated with a purple-brown to black coloration of stems and ears, termed pseudoblack chaff (PBC). Despite the existence of one conflicting report 
(Mishra et al. 2005), it is generally believed that PBC and $\mathrm{Sr} 2$ show perfect linkage (Kota et al. 2006; Mago et al. 2011a). Expression of the PBC trait is modified by genetic background and environmental conditions, making it an imperfect visual marker for the presence of $S r 2$. PBC is often referred to as "melanism," but the precise nature of the blackening has not yet been reported. PBC was initially observed in field-grown plants in association with stem rust infection; however, it is also observed in apparently uninfected plants, usually in warm, humid conditions, at late stages of reproductive development (Johnson and Hagborg 1943; Sheen et al. 1968).

Here we report that the $S r 2$-mediated resistance responses to both $P$. graminis f. sp. tritici and $B$. graminis f. sp. tritici were characterized by the death and collapse of photosynthetic cells surrounding infection sites. Similarly, the death of photosynthetic cells accompanied the appearance of PBC on stem-exposed internodes and glumes of $\mathrm{Sr} 2+$ wheat genotypes in the absence of pathogen infection. Death of leaf tissue also characterized what appear to be responses mediated by $\mathrm{Sr} 2$ to abiotic stresses such as heat.

\section{MATERIALS AND METHODS}

Plant material. A fine-mapping family was previously established from a cross between the susceptible cultivar CS and a substitution line in which CS chromosome 3B was substituted with Hope chromosome $3 \mathrm{~B}$ carrying the $\mathrm{Sr} 2$ locus, referred to as CS(Hope3B) (Kota et al. 2006). Critical recombinant lines (RLs) defining the $\mathrm{Sr} 2$ locus are described in Mago et al. (2011b). CS(Hope 3B) mutants M71 and M3/2 were identified by screening methods described by Mago et al. (2011b). Both mutants lacked the visual marker, $\mathrm{PBC}$, as well as resistance to stem rust, leaf rust, and powdery mildew. M71 retained the simple sequence repeat marker, gwm533, but lacked DNA markers within and distal to the $S r 2$ locus (data not shown), indicating that it had lost the distal part of chromosome 3BS, including the complete $\mathrm{Sr} 2$ locus. Mutant M3/2 lacked $g w m 533$ and distal 3BS markers.

Stem rust inoculation. Plants were maintained in potting soil in a growth cabinet free of pathogens at $25^{\circ} \mathrm{C}$ during the day $(16 \mathrm{~h}$, $\sim 600 \mu \mathrm{mol} / \mathrm{m}^{2} / \mathrm{s}$ ) and $18^{\circ} \mathrm{C}$ at night $(8 \mathrm{~h}$ ). At heading (Zadoks scale DC50; Zadoks et al. 1974), plants were transferred to a glasshouse at the same temperatures. At first anthesis (Zadoks scale DC60), plants were inoculated with $P$. graminis f. sp. tritici race 98$1,2,3,5,6$, using talc as a vehicle. Rust spores were mixed with talc in a 1:2 ratio. Leaf sheaths and exposed internodes were first misted with water; then the spore mix was applied using a puffer to achieve a thin, even coating of talc on inoculated tissues. Plants were then incubated in a humid chamber for $48 \mathrm{~h}\left(25^{\circ} \mathrm{C}\right.$ during the day, $16 \mathrm{~h} /$ $18^{\circ} \mathrm{C}$ at night) before they were moved to a glasshouse or growth cabinet maintained at $25^{\circ} \mathrm{C}$ during the day $(16 \mathrm{~h})$ and $18^{\circ} \mathrm{C}$ at night. Rust phenotypes were scored 12 to 14 days after inoculation.

Mildew inoculation. Plants of CS(Hope3B) and deletion mutant M71 were maintained in potting soil in a growth cabinet at $25^{\circ} \mathrm{C}$ during the day $\left(16 \mathrm{~h}, \sim 600 \mu \mathrm{mol} / \mathrm{m}^{2} / \mathrm{s}\right)$ and $18^{\circ} \mathrm{C}$ at night $(8 \mathrm{~h})$. At 4 weeks after sowing (late tillering stage, Zadoks scale DC29), the plants were transferred to a glasshouse set at the same temperatures and were infected with a glasshouse isolate of powdery mildew (B. graminis f. sp. tritici) by laying the plants on a bench and shaking infected leaves over them. The mildew isolate was characterized by its interaction with a reference set of wheat genotypes carrying known powdery mildew resistance genes. The isolate was avirulent on wheat genotypes carrying Pm1, Pm3a, $P m 4 a, P m 4 b$, or Pm6. It was virulent on cultivars carrying $P m 2$ or Pm5. We refer to this mildew isolate as $B$. graminis f. sp. tritici isolate CSIRO-BM Avrl, $3 a, 4 a, 4 b, 6$.

Abiotic stress treatments. Petroleum jelly-induced leaf necrosis. Petroleum jelly (Vaseline; Unilever) was applied with the thumb and forefinger to both sides of an $\sim 2$-cm section of a fully expanded leaf of plants at various growth stages that were maintained in a glasshouse at $25^{\circ} \mathrm{C}$ during the day $(16 \mathrm{~h})$ and $18^{\circ} \mathrm{C}$ at night. Responses were monitored visually over subsequent days and were scored and photographed at 8 days after treatment.

Seedling-stage heat shock. Seedlings were grown in $15-\mathrm{cm}$ pots of potting soil in a growth cabinet at $25^{\circ} \mathrm{C}$ during the day $(12 \mathrm{~h}$, $\sim 600 \mu \mathrm{mol} / \mathrm{m}^{2} / \mathrm{s}$, and approximately six seedlings per pot) and $15^{\circ} \mathrm{C}$ at night. At 18 days after sowing (beginning of the tillering stage, Zadoks scale DC21), a 4.5 -h heat shock treatment was administered as follows. In the middle of the light period, the cabinet temperature setting was adjusted from 25 to $40^{\circ} \mathrm{C}$ and the lights were turned off for $4.5 \mathrm{~h}$, after which the growth conditions were restored to normal. Three days later, leaf 1 of the seedlings was scored and photographed.

Stem elongation-stage heat treatment. Seedlings were grown in individual $8-\mathrm{cm}$ tubes of potting soil in a growth cabinet at $25^{\circ} \mathrm{C}$ during the day $\left(16 \mathrm{~h}, \sim 200 \mu \mathrm{mol} / \mathrm{m}^{2} / \mathrm{s}\right)$ and $15^{\circ} \mathrm{C}$ at night. At 5 weeks after sowing (stem elongation stage, Zadoks scale of approximately DC35), a 2-day heat treatment was administered as follows. Plants were moved to a growth cabinet set at $40^{\circ} \mathrm{C}$ during the day $\left(16 \mathrm{~h}, \sim 225 \mu \mathrm{mol} / \mathrm{m}^{2} / \mathrm{s}\right)$ and $30^{\circ} \mathrm{C}$ at night. Control plants were maintained at the original growth conditions.

Fluorescence imaging of photosynthetic leaf area. Fluorescence imaging was performed using a closed fluorescence system (Photon Systems Instruments). Freshly excised leaf segments were dark adapted by being wrapped in foil then maintained at room temperature $\left(\sim 22^{\circ} \mathrm{C}\right)$ for $20 \mathrm{~min}$. Segments were unwrapped in the apparatus, and a fluorometer (Closed FluorCam 800MF) was used to measure the area of each leaf piece that was photosynthetically active. The shutter speed was set to minimum, sensitivity to $85 \%$, actinic 1 and 2 to $60 \%$, and the saturating flash to $100 \%$. Fluorescence images were used to give a visual record of leaf active photosynthetic area.

Microscopy and tissue preparation. Sections were cut by hand from fresh, uninoculated stems of $\mathrm{Sr} 2+$ individuals of the $\mathrm{CS} \times$ CS(Hope3B) mapping family or from rust-inoculated stems of CS(Hope 3B) or cultivar Fielder (Sr2-). Sections were mounted immediately in water or $50 \%$ glycerol and observed using a Leica SP8 confocal microscope with excitation at 405 and $561 \mathrm{~nm}$, with emission collected at 430 to $455 \mathrm{~nm}$ (cell wall autofluorescence $=$ blue), 520 to $545 \mathrm{~nm}$ (autofluorescence from cell damage $=$ green), and 685 to $710 \mathrm{~nm}$ (chloroplast autofluorescence $=$ red).

Trypan blue (TB) staining was performed using the method of Desmond et al. (2008). The TB stain contained $40 \mathrm{mg}$ of TB, $40 \mathrm{ml}$ of $50 \%$ ( $\mathrm{vol} / \mathrm{vol}$ ) glycerol, $20 \mathrm{ml}$ of lactic acid, and $20 \mathrm{ml}$ of phenol. Prior to use, an aliquot of the stain was diluted with two volumes of 95\% ethanol. Three milliliters of diluted stain was added to roundbottomed polypropylene culture tubes. Each tube was preheated in a beaker of boiling water for $1 \mathrm{~min}$ before freshly cut leaf samples were added. Tubes were heated in boiling water for 1 additional min before they were allowed to cool and were stored away from light overnight. Samples were destained in saturated chloral hydrate. Destaining for $<24 \mathrm{~h}$ resulted in staining of fungal structures as well as dead plant cells (Fig. $1 \mathrm{G}$ and $\mathrm{H}$ ), whereas longer destaining resulted in loss of staining by the fungal structures (Fig. 1E and F). Images were recorded in brightfield using either a Leica DMR upright microscope (Fig. 1C and D) or a Zeiss AxioImager microscope (Fig. 1E to H) equipped with digital cameras.

\section{RESULTS}

Sr2-dependent, adult plant-stage resistance to stem rust is accompanied by the death of chlorenchyma cells around infection sites in inoculated leaf sheath. Responses to $P$. graminis f. sp. tritici were examined in three classes of wheat genotypes: those carrying the resistant haplotype at the $S r 2$ locus $(\mathrm{Sr} 2+)$, those carrying the susceptible haplotype $(\mathrm{Sr} 2-)$, or deletion mutants of $\mathrm{CS}$ (Hope3B) lacking the locus (Sr2-). The 
stem rust-susceptible cultivar Fielder ( $\mathrm{Sr} 2-$ ) and parents and RLs of a high-resolution mapping family derived from a cross between the susceptible cultivar CS and the resistant chromosome substitution line, CS(Hope3B), were inoculated with $P$. graminis f. sp. tritici at anthesis. From $\sim 12$ days after inoculation, CS(Hope3B) and $\mathrm{Sr} 2+$
RLs (determined using the tightly linked $\mathrm{Sr} 2$ marker, cs $S r 2$; Mago et al. 2011a) showed resistance, characterized by generally small pustules surrounded by the dark coloration characteristic of $\mathrm{PBC}$ on both exposed internodes and leaf sheath (Fig. 2A and B; Table 1).
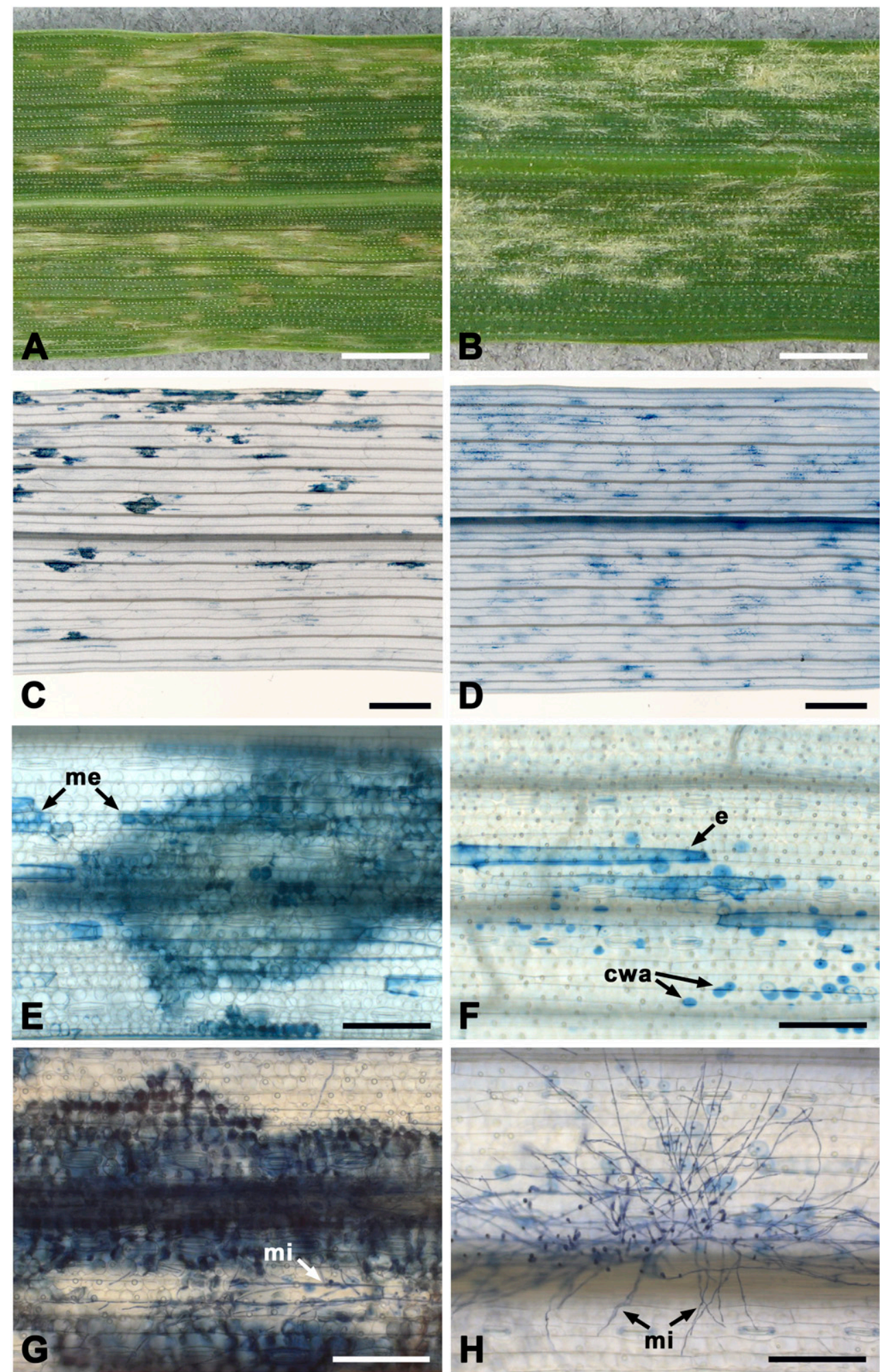

Fig. 1. $S r 2$-mediated, late tillering-stage resistance to powdery mildew is associated with the death of mesophyll cells around infection sites. Patches of necrosis were visible around mildew infection sites in A, Sr2+ Chinese Spring chromosome 3B substituted with Hope chromosome 3B carrying the $S r 2$ locus [CS(Hope3B)] but not in B, Sr2- deletion mutant M71 at 5 days after inoculation with Blumeria graminis f. sp. tritici. C and E, Trypan blue staining revealed dead mesophyll cells (me) in CS(Hope3B). D and F, Stained features in M71 corresponded to occasional dead epidermal cells (e) and cell wall appositions (cwa). Trypan blue staining using a slightly different protocol stained fungal as well as plant structures, revealing the close association between mildew (mi) and plant cell responses in G, CS(Hope3B) and $\mathbf{H}$, mutant M71. Scale bars: A to $\mathrm{D}=2 \mathrm{~mm}$; E to $\mathrm{H}=0.1 \mathrm{~mm}$. 
Fielder, CS, and Sr2- RLs showed a susceptible response, developing large, numerous rust pustules on inoculated leaf sheaths and exposed internodes (Fig. 2C and D; Table 1). Confocal fluorescence microscopy on fresh hand-cut transverse sections through rust pustules on the inoculated sheath of $\mathrm{CS}$ (Hope3B) displayed blue-green autofluorescence characteristic of cell death, with little or no active chlorophyll in photosynthetic cells under and adjacent to the rust pustules. In these regions, cell morphology was collapsed and disrupted (Fig. 2E, left). In contrast, an adjacent, uninfected segment of the same section of CS(Hope3B) leaf sheath showed extensive red fluorescence, apparently intact cells, and no rust pustules (Fig. 2E, right). Sections of the inoculated sheath of Sr2- cultivar Fielder showed that the green tissue under and adjacent to erupting rust pustules contained active chlorophyll (red fluorescence, Fig. 2F).

Sr2-dependent, tillering-stage resistance to powdery mildew involves cell death. CS(Hope3B) and Sr2+ RLs displayed moderate resistance to a local isolate of $B$. graminis $\mathrm{f}$. $\mathrm{sp}$.
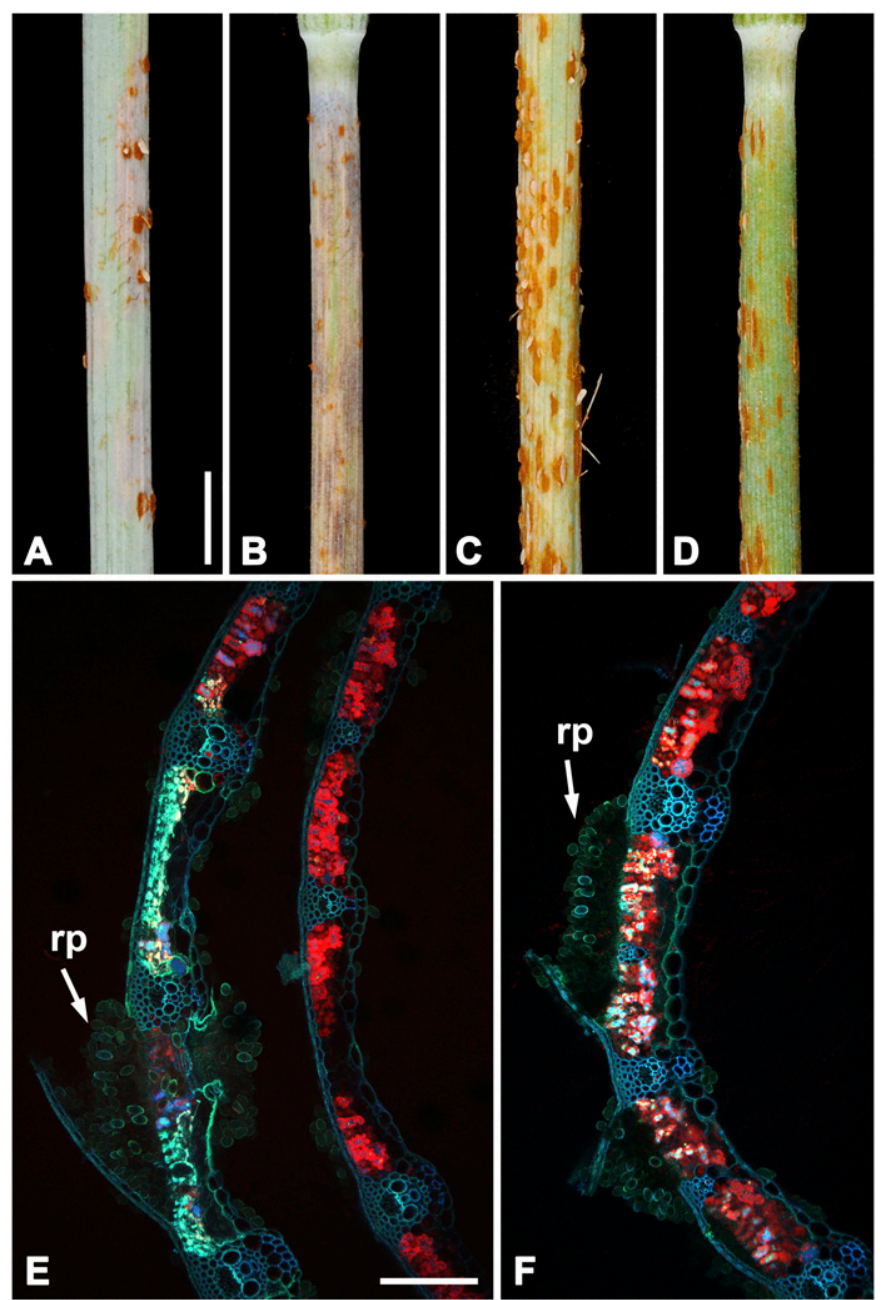

Fig. 2. Death of photosynthetic cells occurs around stem rust infection sites in inoculated leaf sheath of $S r 2+$ wheat genotypes. Rust responses on A and B, Sr2+ Chinese Spring chromosome 3B substituted with Hope chromosome 3B carrying the $S r 2$ locus [CS(Hope3B)] and C and D, Sr2-RL119 were photographed at $\sim 20$ days after inoculation with Puccinia graminis $\mathrm{f}$. sp. tritici. The leaf sheath is shown in $\mathrm{A}$ and $\mathrm{C}$, whereas the corresponding subtending internode is shown in B and D. Confocal microscopy at 12 days after inoculation of fresh sections through the $\mathbf{E}$, rust-infected leaf sheath of CS(Hope3B) (left) showed blue-green autofluorescence characteristic of cell death, whereas sections through the F, rust-infected sheath of $\mathrm{Sr} 2$ - cultivar Fielder showed mainly red fluorescence characteristic of chlorophyll in the active conformation adjacent to rust pustules (rp). Uninfected areas of $\mathrm{CS}$ (Hope3B) sheath also showed active chlorophyll and no cell death (top left in E). Scale bars: $\mathrm{A}=$ $5 \mathrm{~mm}$ for $\mathrm{A}$ to $\mathrm{D} ; \mathrm{E}=0.2 \mathrm{~mm}$ for $\mathrm{E}$ and $\mathrm{F}$. tritici from the late tillering stage of plant growth $(\sim 4$ weeks after sowing at $25^{\circ} \mathrm{C}$ ). CS and $S r 2-$ RLs and two deletion mutants of $\mathrm{CS}($ Hope $3 \mathrm{~B}$ ) that lacked $\mathrm{Sr} 2$ markers were susceptible at this stage. All of the genotypes were fully susceptible at the seedling stage, regardless of their $\mathrm{Sr} 2$ haplotype (Table 1). The Sr2-linked resistance to mildew in late tillering-stage plants was characterized at the cellular level by death of mesophyll cells below sites of infection in the leaf epidermis. At 5 days after inoculation, inoculated $\mathrm{CS}(\mathrm{Hope} 3 \mathrm{~B})$ leaves showed limited mildew growth that was closely associated with visibly collapsed areas of leaf tissue (Fig. 1A). TB staining revealed that these areas of collapsed tissue corresponded to patches of dead mesophyll cells (Fig. 1C). On the other hand, mildew colonies were profuse on leaves of the susceptible Sr2- deletion mutant, M71 (Fig. 1B). TB-stained features also appeared on leaves of M71 at 5 days after inoculation (Fig. 1D); however, the staining was qualitatively different between M71 and CS(Hope3B). Visualization at higher magnification revealed that the staining was predominantly of mesophyll cells in CS(Hope3B) (Fig. 1E), whereas staining was almost entirely of cell wall appositions and dead epidermal cells in M71 leaves (Fig. $1 \mathrm{~F})$, with rare, stained mesophyll cells.

The TB staining protocol used in the work described above resulted in staining of only plant tissue. However, we subsequently established that using the method described, followed by observation under the microscope within 16 to $24 \mathrm{~h}$ of destaining in chloral hydrate, showed staining of mildew structures as well as dead plant cells. Staining of mildew structures disappeared if leaves were left in chloral hydrate for $>24 \mathrm{~h}$, as in the experiment described above. In a separate experiment, TB staining, followed by examination immediately after clearing of CS(Hope3B) and CS leaves at 5 days after inoculation, illustrated the relationship between fungal mycelia and the TB-stained plant features. In CS(Hope3B), mildew hyphae and conidia were seen in close association with the patches of dead mesophyll cells (Fig. 1G). In Sr2-CS, mildew hyphae and conidia were more abundant than in $\mathrm{CS}($ Hope $3 \mathrm{~B})$, and they were closely associated with stained cell wall appositions and occasional dead epidermal cells (Fig. 1H).

PBC on $\mathrm{Sr} 2+$ wheat stems can occur in the absence of stem rust infection and corresponds to cell death. Parents and RLs of the CS $\times$ CS(Hope3B) mapping family as well as $\mathrm{Sr} 2$ deletion mutants were grown in a temperature-controlled glasshouse in which spontaneous $P$. graminis f. sp. tritici and B. graminis f. sp. tritici infection was prevented by spraying with fungicide. PBC was commonly seen on stems and ears of CS(Hope $3 B$ ) and $\mathrm{Sr} 2+\mathrm{RLs}$ at growth temperatures around or above $25^{\circ} \mathrm{C}$ (Fig. 3A to $\mathrm{C}$; Table 1). PBC was never seen on plants with the susceptible or deleted $\mathrm{Sr} 2$ haplotypes (data not shown).

Fresh, hand-cut, transverse sections of stems at an early stage of PBC development (around the time of anthesis) were observed using confocal fluorescence microscopy. Sections cut across regions of exposed internodes that were incompletely affected by PBC (e.g., at the arrow in Fig. 3C) showed red autofluorescence indicative of active chlorophyll in the files of green, unaffected photosynthetic cells (chlorenchyma; Fig. 3D, lower half, and E). In contrast, chlorenchyma in the PBC-affected parts of the stem displayed greenish autofluorescence indicative of cell death (Fig. $3 \mathrm{D}$, upper half, F, and G). The morphology of the cells in the parts of the stems that were strongly affected by $\mathrm{PBC}$ was clearly disrupted (arrow in Fig. 3D and G). PBC on glumes of the ear also corresponded to loss of chlorophyll fluorescence, autofluorescence of dead cells, and loss of cell integrity (data not shown).

Application of petroleum jelly to $\mathrm{Sr} 2+$ wheat leaves causes tissue death. It was observed that application of rust spores to wheat stems using sticky tape occasionally caused necrosis on $\mathrm{Sr} 2+$ but not $\mathrm{Sr} 2-\mathrm{CS} \times \mathrm{CS}($ Hope3B) RLs. Similar effects were observed with sticky-tape control treatments lacking rust spores (data not shown). In further investigating this effect, it was discovered that application of petroleum jelly to both sides of a 
section of $\mathrm{Sr} 2+$ leaf produced necrosis of the covered tissue (Fig. 4A; Table 1; Supplementary Fig. S1), whereas CS, Sr2- RLs, and $S r 2-$ deletion mutants were unaffected by the treatment (Fig. 4B; Table 1). The petroleum jelly-induced necrosis in leaves of CS(Hope 3B) and Sr2+ RLs developed over a period of several days, depending on the growth temperature and the age of the plants when the treatment was applied. Responses were scored at 8 days after treatment (Table 1). Necrosis could be elicited on leaf 1 in seedlings at the three-leaf stage, but it generally developed faster in older plants and was most reliably observed at growth temperatures of $25^{\circ} \mathrm{C}$ or more in strong light. Vaseline treatment of leaves of $\mathrm{Sr} 2+$ wheat cultivars produced variable results, indicating that the response, like other $\mathrm{Sr} 2$-associated phenotypes, was modified by genetic background. Vaseline application to exposed internodes of the stems of $\mathrm{Sr} 2+\mathrm{CS}($ Hope $3 \mathrm{~B}$ ) promoted PBC-like symptoms (Fig. 4C), whereas the treatment had no effect on stems of $\mathrm{Sr} 2-$ deletion mutant M3/2 (Fig. 4D) or Sr2- cultivar Fielder (data not shown).

Leaf tissue death is induced by heat treatments in $\mathbf{S r} \mathbf{2 +}$ wheat genotypes. Leaf necrosis was often observed during hot weather in $\mathrm{Sr} 2+$ wheat genotypes grown in the glasshouse over the summer. Subsequently, several high-temperature treatments in controlled-temperature growth cabinets were found to elicit leaf necrosis in $\mathrm{Sr} 2+$ but not $\mathrm{Sr} 2$ - wheat genotypes. A 4.5 -h heat shock at $40^{\circ} \mathrm{C}$, in the absence of light, was administered to seedlings at the beginning of the tillering stage (Zadoks scale DC21; Zadoks et al. 1974), and phenotypes were scored 3 days after treatment. The heat shock produced characteristic flecked necrotic lesions on leaf 1 and the distal part of leaf 2 in $S r 2+$ cultivars Sunstate, CS(Hope3B) (Fig. $4 \mathrm{E}$ and F), and Hope and recombinants RL7, 10, and 114 (Table 1). Conversely, the treatment had no visible effect on seedlings of $\mathrm{Sr} 2-$ wheat genotypes, for example, in cultivars Janz, CS (Fig. 4G and H), or Marquis or critical recombinant RL119 or deletion mutant M71 (Table 1).

In separate experiments, heat treatments were performed on older plants of Sr2+ RL7 and on Sr2- RL119. Plants were grown in a growth cabinet at $25^{\circ} \mathrm{C}$ for $16 \mathrm{~h}$ during the day and $18^{\circ} \mathrm{C}$ at night for 5 weeks (to the jointing stage of stem elongation, DC35; Zadoks et al. 1974). A heat treatment was applied by transferring four plants of each genotype to a cabinet set at $40^{\circ} \mathrm{C}$ for $16 \mathrm{~h}$ during the day and $30^{\circ} \mathrm{C}$ at night. At $24 \mathrm{~h}$ after transfer, leaves were sampled for fluorescence imaging of photosynthetic activity and for TB staining. Representative images in Figure 5 illustrate that the heat treatment (Fig. 5A, C, E, G, I, and K) resulted in loss of photosynthetic activity and death of mesophyll cells in Sr2+ RL7 plants (Fig. 5C, G, and K) but not in the $S r$ - RL119 plants (Fig. 5A, $\mathrm{E}$, and I). It should be noted that whereas red-colored fluorescence is associated with active chlorophyll in Figures 1 and 3, the red color in Figure 5A to D is attributable to outlining of photosynthetic leaf areas detected by the fluorescence imager used in this experiment. The red outline around the leaf piece in Figure 5A, B, and D indicates that essentially all of the sample is perceived as a single photosynthesizing area by the imager software. The dense, red outlining in Figure 5C shows that the photosynthetic area is degraded and fragmented in the leaf from a Sr2+ RL7 plant after 24-h heat treatment.

\section{DISCUSSION}

$\mathrm{Sr} 2$ has been a key component of effective stem rust resistance in wheat for almost 100 years. The gene is classed as "slow rusting" APR, a class of resistance not believed to involve the hypersensitive response (HR) commonly associated with the NLR-type disease resistance genes. The data presented here demonstrate that $\mathrm{Sr} 2$-mediated resistance to both $P$. graminis f. sp. tritici and $B$. graminis f. sp. tritici is associated with death of host photosynthetic cells around pathogen infection sites. More notably, the $\mathrm{Sr} 2$ locus is shown to cosegregate in critical recombinants of a fine-mapping population with necrotic responses apparently triggered by abiotic stresses, including heat. The nature of the cell death observed here in response to both biotic and abiotic stresses was indistinguishable using the assays reported.

PBC, now known to occur in both the presence and absence of $P$. graminis f. sp. tritici infection, has long been used as a visual marker of $S r 2$ by wheat breeders; however, the nature of the blackening has not yet been fully investigated. Most reports refer to PBC as melanism, thought to be caused by accumulation of brown pigment, although references to necrosis can be found in the older literature. McFadden (1939) reported that PBC was associated with stem rust infection and referred to $\mathrm{PBC}$ as "brown necrosis." $\mathrm{He}$ proposed the term "photologic resistance" to reflect the finding that $\mathrm{Sr} 2$ stem rust resistance was seen in inoculated tissues normally exposed to light (e.g., in the leaf sheath) but not in enclosed internode tissue inoculated by injecting rust spores under the sheath (McFadden 1939). Forty years later, stem PBC in rust-inoculated, field-grown plants was described by Hare and McIntosh (1979) as

TABLE 1. Phenotypes of $S r 2+/-$ genotypes in response to biotic and abiotic stresses

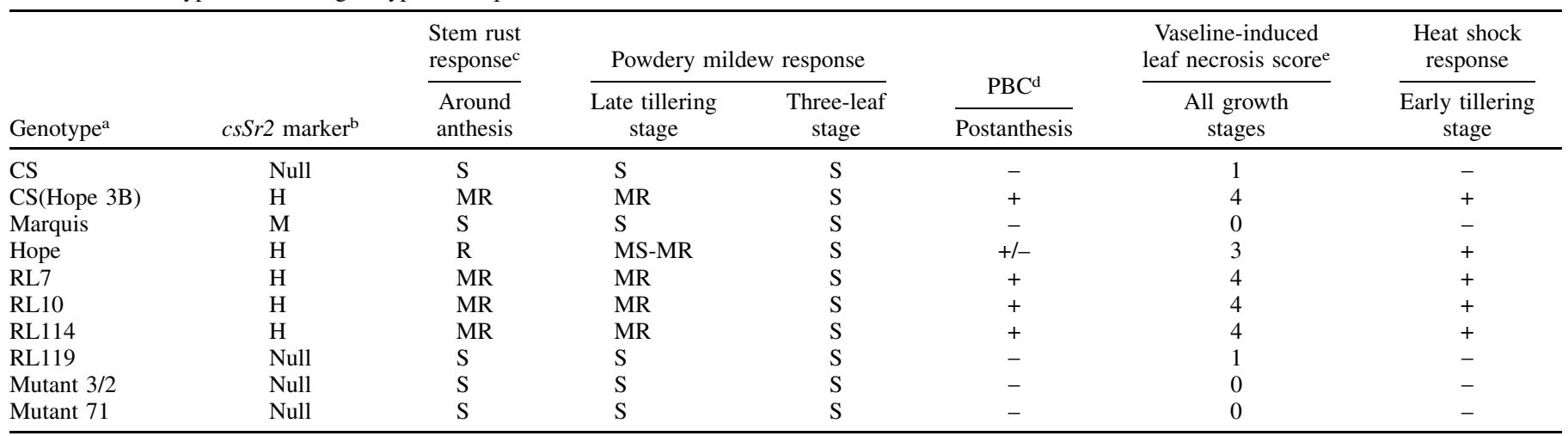

a CS = Chinese Spring, CS(Hope 3B) = Chinese Spring chromosome 3B substituted with Hope chromosome 3B carrying the $S r 2$ locus, and RL = recombinant line.

b The csSr2 marker is described in Mago et al. (2011a). Null = did not amplify with primers (indicating the CS allele), $\mathrm{H}=\mathrm{Hope}$ allele, and $\mathrm{M}=\mathrm{Marquis}$ allele. RL119 carries the Hope allele at markers proximal to RKO_1, inclusive; and the CS allele at markers distal to MSF_2, inclusive, across the entire Sr2 locus (see Fig. 1 in Mago et al. 2011a).

c Stem rust and powdery mildew responses were as follows: $\mathrm{S}=$ sensitive, $\mathrm{MR}=$ moderately resistant, $\mathrm{R}=$ resistant, and MS = moderately sensitive.

d Pseudo-black chaff (PBC) scores were as follows: the plus sign (+) indicates that PBC was present in most plants in most experiments, the minus sign (-) indicates that $\mathrm{PBC}$ was always absent, and the plus/minus sign (+/-) indicates that $\mathrm{PBC}$ was occasionally present.

e Induced leaf necrosis scores were as follows: $0=$ no visible necrosis; $1=$ chlorosis, or rare, very small flecks of necrosis; $2=$ obvious necrosis, $<50 \%$ of treated region dead; $3=>50 \%$ of treated region dead; and $4=100 \%$ of treated region dead. At least five plants per genotype were tested for each phenotype, and all screening was repeated several times with various combinations of genotypes. 
accumulation of pigment in photosynthetic cells that appeared "disrupted and presumably dead."

The results presented here support the early descriptions of PBC as necrosis of photosynthetic cells. We demonstrate that the brown $\mathrm{PBC}$ seen on the leaf sheath of $\mathrm{Sr} 2+\mathrm{CS}$ (Hope $3 \mathrm{~B}$ ), around stem rust pustules (Fig. 2A), is attributable to the death of chlorenchyma (Fig. 2E). Similarly, PBC, occurring in the absence of rust, on exposed stem internodes is shown to be a result of death of chlorenchyma (Fig. 3). The fact that it is photosynthetic cells that die may explain McFadden's observation that the enclosed internode (an organ that
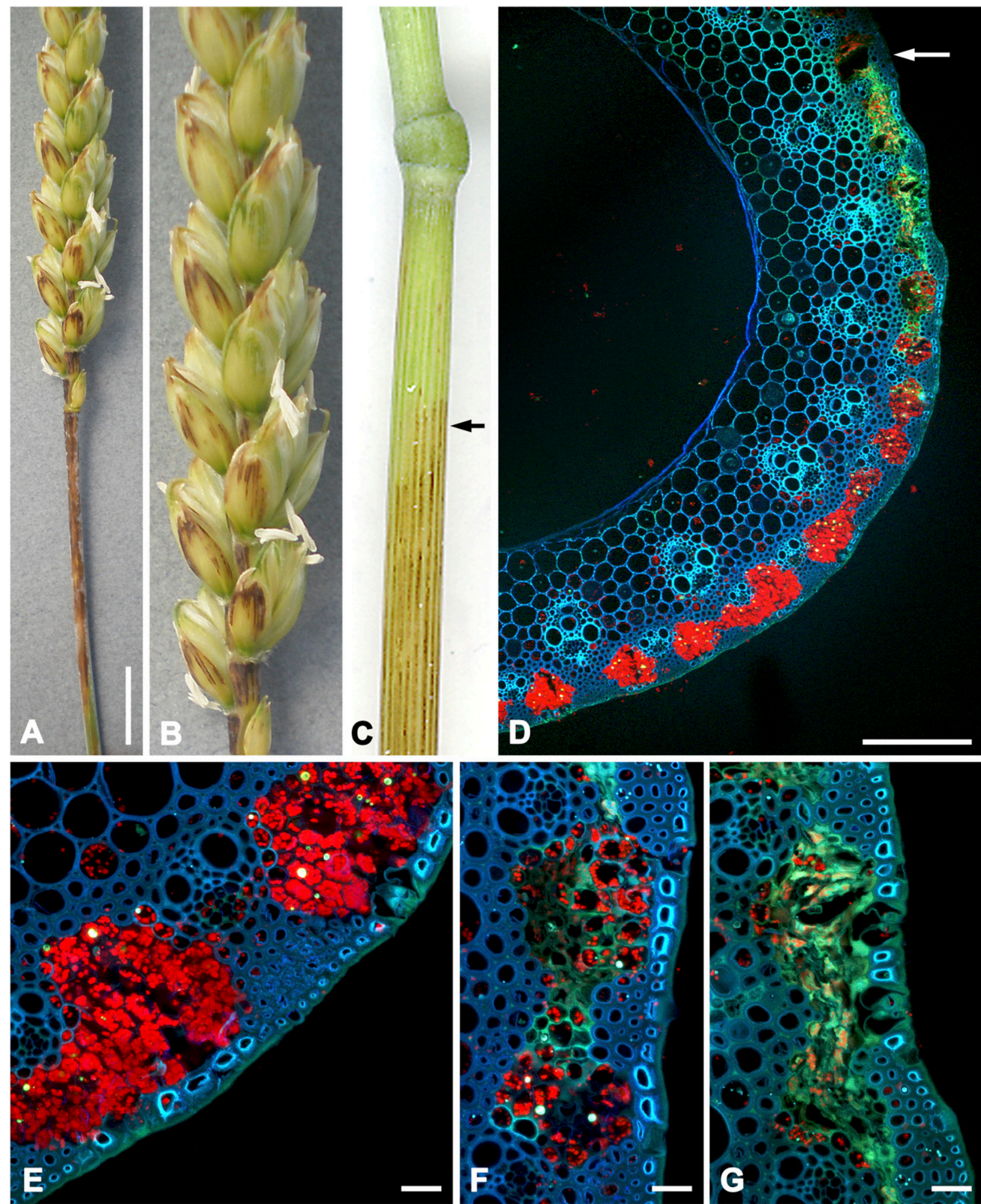

Fig. 3. Pseudo-black chaff (PBC) in nonpathogen-inoculated stems of $S r 2+$ wheat genotypes corresponds to the death of photosynthetic cells. A, B, and C, PBC was visible on otherwise green tissues in stems and ears of Chinese Spring chromosome 3B substituted with Hope chromosome 3B carrying the Sr2 locus $\left[\mathrm{CS}\left(\right.\right.$ Hope3B)] from about the stage of anthesis, at growth temperatures at or above $25^{\circ} \mathrm{C}$. Confocal fluorescence microscopy of fresh sections across an affected internode (e.g., at the site of the arrow in C) showed red autofluorescence corresponding to $\mathbf{D}$ and $\mathbf{E}$, green, photosynthetically active chlorenchyma (D, lower left, and E), and D, F, and G, yellow-green autofluorescence associated with cell death in PBC-affected cells (D, upper right, F, and G). Chlorenchyma cell morphology was completely collapsed in severely affected parts of the stem (arrow in D). Scale bars: $A=5 \mathrm{~mm} ; \mathrm{D}=0.2 \mathrm{~mm} ; \mathrm{E}$ to $\mathrm{G}=20 \mu \mathrm{m}$. 
does not contain photosynthetic chlorenchyma) did not display PBC or apparent resistance to $P$. graminis f. sp. tritici.

Rusts invade a plant host by first penetrating through stomata, followed by invagination of a feeding haustorium into a mesophyll cell. The death of mesophyll in response to $P$. graminis f. sp. tritici inoculation of $\mathrm{Sr} 2$ wheat genotypes may therefore be initiated directly by attempted haustorium formation by the rust pathogen. P. graminis f. sp. tritici resistance mediated by wheat NLR genes can produce a range of resistance phenotypes, as illustrated in McIntosh et al. (1995). These responses range from barely visible hypersensitive flecks, with no rust sporulation, to obvious uredia surrounded by quite extensive regions of chlorosis or necrosis. These responses are generally scored 10 to 18 days after inoculation. Thus, the cell death observed here around $P$. graminis $\mathrm{f}$. sp. tritici uredia on the $\mathrm{Sr} 2+$ leaf sheath and exposed stem internode is similar in timing but generally larger in extent than the resistance responses to $P$. graminis $\mathrm{f}$. sp. tritici scored on leaves of wheat seedlings carrying NLR genes. The brown coloration of the dead areas that characterize $S r 2$-mediated $P$. graminis f. sp. tritici resistance and nonrust-associated $\mathrm{PBC}$ on stems may partly be explained by the fact that stem tissues (and presumably glumes) contain more structural polyphenolic compounds than do leaves. However, the dark-colored PBC in stems and glumes appears to be unique to $\operatorname{Sr} 2$ wheats, rather than a general feature of death of photosynthetic cells in these plant organs, possibly indicating upregulation of pathways producing polyphenolic compounds in the $\mathrm{Sr}$-mediated response.

Death of mesophyll was closely associated with $B$. graminis $\mathrm{f}$. sp. tritici infection sites in leaves of tillering-stage plants of $\mathrm{Sr} 2+$ wheat genotypes (Fig. 1). Powdery mildew invades a plant host by invaginating a haustorium into epidermal cells. In wheat, resistance to $B$. graminis f. sp. tritici mediated by NLR resistance genes has been reported to involve an HR characterized by rapid death of invaded epidermal cells before establishment of a haustorium, in the case of Pm3b (Yahiaoui et al. 2004). Similarly, in barley, resistance gene $M l g$ blocked infection by an avirulent $B$. graminis f. sp. hordei isolate via rapid HR of infected epidermal cells. On the other hand, infection of barley bearing a different NLR gene, Mla12, frequently resulted in successful establishment of a haustorium in invaded epidermal cells, with propagation of the pathogen being halted by HR of adjacent mesophyll cells (Hucklehoven et al. 1999), similar to the situation described here for $B$. graminis $\mathrm{f}$. sp. tritici infection of $\mathrm{CS}$ (Hope 3B). In the latter case, however, infection frequently progressed to the stage of conidia formation, and mesophyll cell death spread beyond leaf cells in obvious contact with mildew. Thus, the nature of the cell death observed in $\mathrm{Sr} 2$-mediated responses to $P$. graminis f. sp. tritici and $B$. graminis f. sp. tritici bears some similarities to the HR triggered by recognition of these pathogens by cereal NLRs.

One obvious difference between the $\mathrm{Sr} 2$-mediated responses described here and those triggered by the plant defense NLRs lies in the observation that $\mathrm{Sr} 2$-mediated cell death is also triggered in the apparent absence of pathogens. A number of abiotic stresses induced visible necrosis in $S r 2+$ leaves. A brief, high-temperature treatment of wheat seedlings at the very early tillering stage caused a characteristic flecked necrosis on leaves 1 and 2 of $S r 2+$ but not $\mathrm{Sr} 2$ - genotypes. This response was growth-stage dependent. Delivering the heat shock treatment to seedlings at the three-leaf stage produced no response. Thus, this $S r 2$ phenotype was growthstage dependent, as with the $B$. graminis f. sp. tritici and $P$. graminis f. sp. tritici resistance responses. Longer heat treatments of older plants produced a decline in the photosynthetic activity of leaves, followed by the death of mesophyll cells, and eventual appearance of patches of necrosis. The mechanism of these temperature responses is unknown. Similarly, the mechanism of the cell death response in leaves and stems to application of petroleum jelly is unknown. It is possible that the latter effects are mediated through subtle temperature increases, as a result of blocking stomatal gas exchange. The age dependence of Sr2-mediated cell death responses may suggest a link with senescence-related cell death, but this will require further investigation. Preliminary stem rust infection experiments at a range of temperatures did not support the proposition that $S r 2$-mediated $P$. graminis f. sp. tritici resistance is temperature sensitive (data not shown).
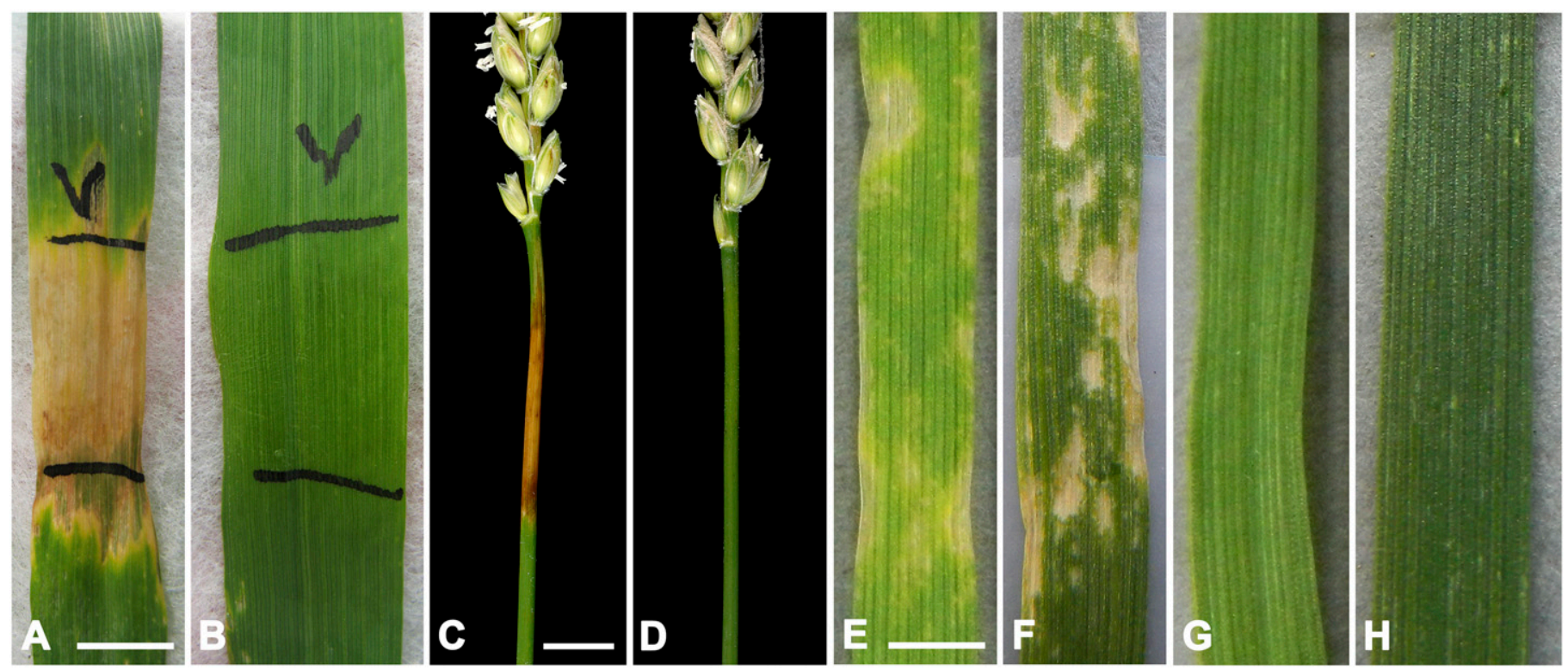

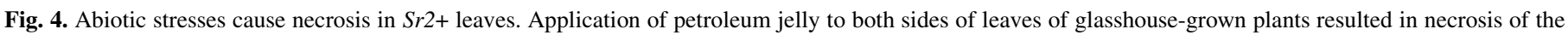

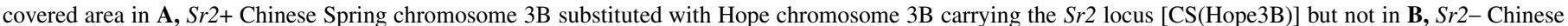

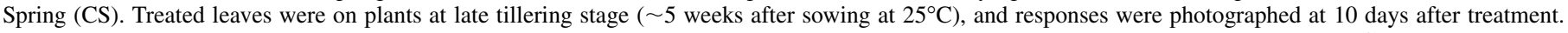

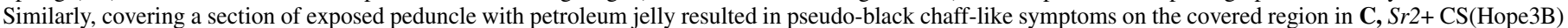

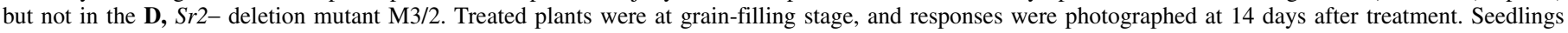

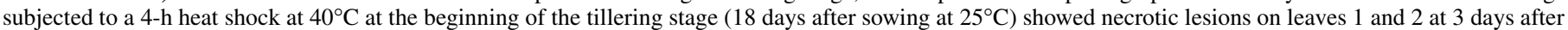

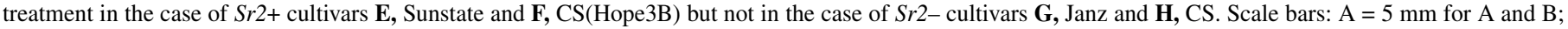
$\mathrm{C}=10 \mathrm{~mm}$ for $\mathrm{C}$ and $\mathrm{D} ; \mathrm{E}=2 \mathrm{~mm}$ for $\mathrm{E}$ to $\mathrm{H}$. 

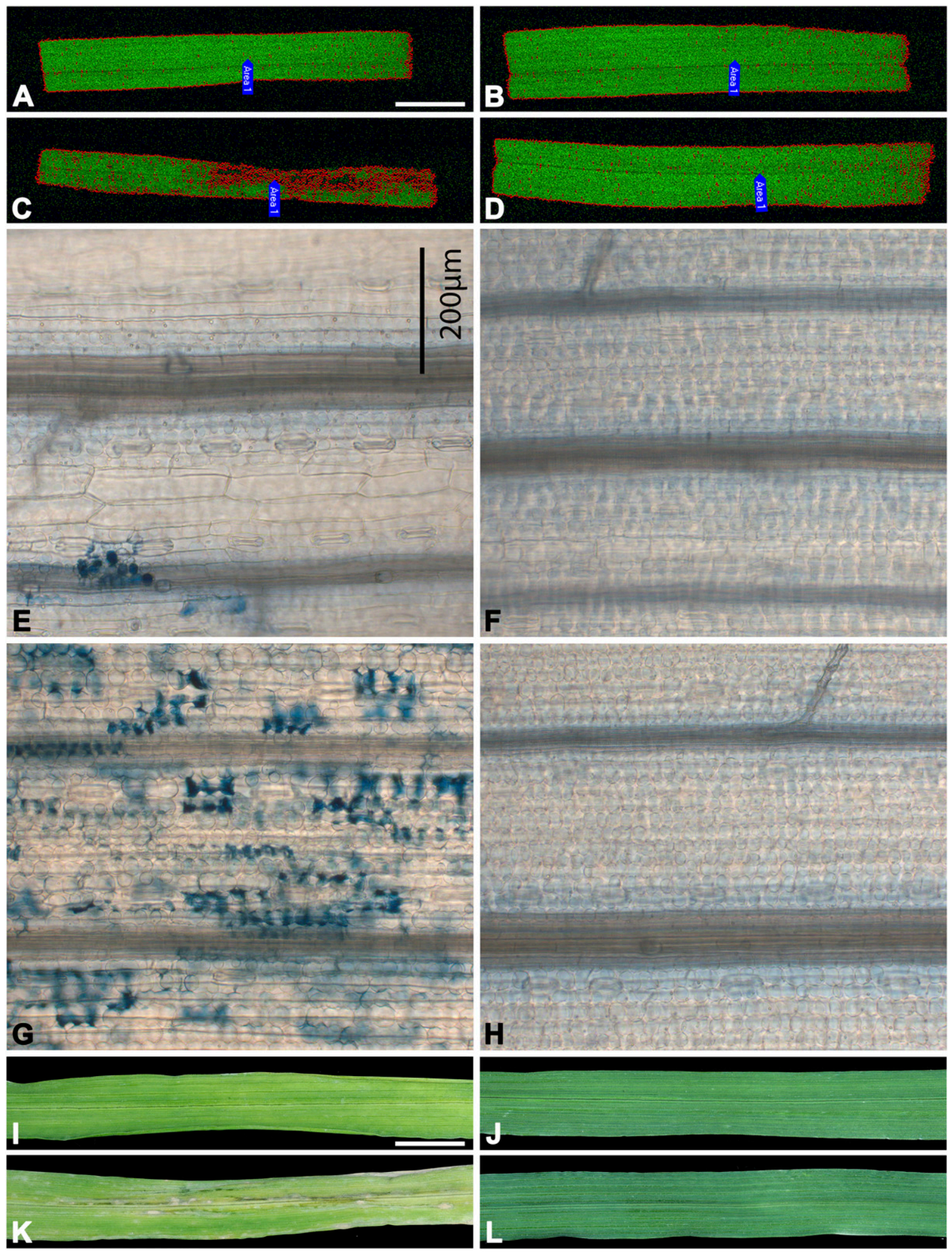

Fig. 5. Heat stress causes loss of photosynthetic activity and death of leaf mesophyll in $S r 2+$ recombinant line 7 (RL7) but not in $S r 2-$ RL119. Plants of $S r 2+/-$ RLs were grown for 5 weeks in temperature-controlled growth cabinets at $25^{\circ} \mathrm{C}$ for $16 \mathrm{~h}$ during the day and $18^{\circ} \mathrm{C}$ at night. At jointing stage, half of the plants were transferred to $40^{\circ} \mathrm{C}$ for $16 \mathrm{~h}$ during the day and $30^{\circ} \mathrm{C}$ at night. $\mathbf{A}, \mathbf{C}, \mathbf{E}, \mathbf{G}, \mathbf{I}$, and $\mathbf{K}$, Representative images of leaves of plants subjected to the hightemperature growth conditions ( $n=4$ per genotype). $\mathbf{B}, \mathbf{D}, \mathbf{F}, \mathbf{H}, \mathbf{J}$, and $\mathbf{L}$, Representative images of leaves of plants kept at control growth conditions $(n=4$ per genotype). A to D are fluorescence images showing the photosynthetically active leaf area of a midsection of the third youngest leaves $24 \mathrm{~h}$ after the initiation of the A and $\mathrm{C}$, high-temperature $\left(40^{\circ} \mathrm{C} / 30^{\circ} \mathrm{C}, \sim 225 \mu \mathrm{mol} / \mathrm{m}^{2} / \mathrm{s}\right)$ or B and D, control $\left(25^{\circ} \mathrm{C} / 18^{\circ} \mathrm{C}, \sim 225 \mu \mathrm{mol} / \mathrm{m}^{2} / \mathrm{s}\right)$ treatments (A and B, Sr2- RL119; C and D, $S r 2+$ RL7). The imaging software outlines photosynthetic areas in red. The dense red coloring in C indicates fragmentation of the photosynthetic leaf area and a reduction in its extent. E and F are representative trypan blue-stained sections showing death of mesophyll cells to a far greater extent in RL7 than in RL119 $24 \mathrm{~h}$ after initiation of the heat treatment: E and F, Sr2- RL119; G and H, Sr2+ RL7; E and G, high temperature; and F and H, control treatments, respectively. After 3 days of the heat treatment, leaves (midsection of the third youngest leaf) were visibly more damaged in RL7 than in RL119 (images K and I, respectively), whereas leaves of both genotypes were healthy after 3 days of growth in the control conditions (J, RL119; L, RL7). Scale bars: A = 10 mm for A to $\mathrm{D} ; \mathrm{I}=10 \mathrm{~mm}$ for $\mathrm{I}$ to $\mathrm{L}$. 
In summary, the results presented here demonstrate that $\mathrm{Sr} 2$ mediated $P$. graminis f. sp. tritici resistance is not "slow rusting," without the involvement of necrosis, as previously believed (Ellis et al. 2014; Singh et al. 2011b). Rather, $S r 2$-mediated resistance to $P$. graminis f. sp. tritici and B. graminis f. sp. tritici is accompanied by necrosis that bears similarities with the HR-type necrosis that is key to the action of NLR plant disease resistance genes. Although the gene or genes responsible for $S r 2$ phenotypes are not yet identified, the sequence of the $\mathrm{Sr} 2$ genomic region indicates that no NLR genes reside at the locus (Mago et al. 2014). The data presented here suggest that $\mathrm{Sr} 2$ protein(s) may be involved in a pathway mediating plant cell death in wheat, which connects with pathways sensing either biotic or abiotic stresses. The $S r 2$ locus has long been reported to confer the most effective stem rust resistance when it is present as part of a "complex" of genes (Singh et al. 2011a). In one instance, it was demonstrated that the relatively weak seedling resistance to $P$. graminis $\mathrm{f}$. $\mathrm{sp}$. tritici conferred by NLR gene $\operatorname{Sr} 33$ is potentiated by the presence of $\operatorname{Sr} 2$ (Ayliffe et al. 2013). It is possible that $\mathrm{Sr} 2$ may constitute a component(s) of a pathway interacting with the wheat immune system downstream of NLRs that sense pathogen attack.

\section{LITERATURE CITED}

Ayliffe, M., Periyannan, S. K., Feechan, A., Dry, I., Schumann, U., Wang, M.-B., Pryor, A., and Lagudah, E. 2013. A simple method for comparing fungal biomass in infected plant tissues. Mol. Plant-Microbe Interact. 26: 658-667.

Desmond, O. J., Manners, J. M., Stephens, A. E., Maclean, D. J., Schenk, P. M., Gardiner, D. M., Munn, A. L., and Kazan, K. 2008. The Fusarium mycotoxin deoxynivalenol elicits hydrogen peroxide production, programmed cell death and defence responses in wheat. Mol. Plant Pathol. 9: 435-445.

Ellis, J. G., Lagudah, E. S., Spielmeyer, W., and Dodds, P. N. 2014. The past, present and future of breeding rust resistant wheat. Front. Plant Sci. 5:641.

Fu, D., Uauy, C., Distelfeld, A., Blechl, A., Epstein, L., Chen, X., Sela, H., Fahima, T., and Dubcovsky, J. 2009. A kinase-START gene confers temperaturedependent resistance to wheat stripe rust. Science 323:1357-1360.

Hare, R. A., and McIntosh, R. A. 1979. Genetic and cytogenetic studies of durable adult-plant resistances in Hope and related cultivars to wheat rusts. Z. Planzenzüchtung 83:350-367.

Hueckelhoven, R., Fodor, J., Preis, C., Kogel, K.-H. 1999. Hypersensitive cell death and papilla formation in barley attacked by the powdery mildew fungus are associated with hydrogen peroxide but not with salicylic acid accumulation. Plant Physiol. 119:1251-1260.

Johnson, T., and Hagborg, W. A. F. 1943. Melanism in wheat induced by high temperature and humidity. Can. J. Res. 22:7-10.

Kota, R., Spielmeyer, W., McIntosh, R. A., and Lagudah, E. S. 2006. Fine genetic mapping fails to dissociate durable stem rust resistance gene $\mathrm{Sr} 2$ from pseudo-black chaff in common wheat. Theor. Appl. Genet. 112:492-499.

Krattinger, S. G., Lagudah, E. S., Spielmeyer, W., Singh, R., Huerta-Espino, J., McFadden, H., Bossolini, E., Selter, L. L., and Keller, B. 2009. A putative $\mathrm{ABC}$ transporter confers durable resistance to multiple fungal pathogens in wheat. Science 323:1360-1363.

Lagudah, E. S. 2011. Molecular genetics of race non-specific rust resistance in wheat. Euphytica 179:81-91.

Mago, R., Simkova, H., Brown-Guedira, G., Dreisigacker, S., Breen, J., Jin, Y., Singh, R., Appels, R., Lagudah, E. S., Ellis, J., Dolezel, J., and Spielmeyer, W. 2011a. An accurate DNA marker assay for stem rust resistance gene $\mathrm{Sr} 2$ in wheat. Theor. Appl. Genet. 122:735-744.

Mago, R., Tabe, L., McIntosh, R. A., Pretorius, Z., Kota, R., Paux, E., Wicker, T., Breen, J., Lagudah, E. S., Ellis, J. G., and Spielmeyer, W. 2011b. A multiple resistance locus on chromosome arm 3BS in wheat confers resistance to stem rust $(\mathrm{Sr} 2)$, leaf rust $(\mathrm{Lr} 27)$ and powdery mildew. Theor. Appl. Genet. 123:615-623.

Mago, R., Tabe, L., Vautrin, V., Šimková, H., Kubaláková, M., Upadhyaya, N., Berges, H., Kong, X., Breen, J., Doležel, J., Appels, R., Ellis, J., and Spielmeyer, W. 2014. Major haplotype divergence including multiple germin-like protein genes, at the wheat $\mathrm{Sr} 2$ adult plant stem rust resistance locus. BMC Plant Biol. 14:379.

McFadden, E. S. 1930. A successful transfer of emmer characteristics to vulgare wheat. J. Am. Soc. Agron. 22:1020-1034.

McFadden, E. S. 1939. Brown necrosis, a discolouration associated with rust infection in certain rust resistant wheats. J. Agric. Res. 58:805-819.

McIntosh, R. A., Wellings, C. R., and Park, R. F. 1995. Wheat Rusts: An Atlas of Resistance Genes. CSIRO Publications, East Melbourne, Victoria, Australia.

Mishra, A. N., Kaushal, K., Yadav, S. R., Shirsekar, G. S., and Pandey, H. N. 2005. The linkage between the stem rust resistance gene $\mathrm{Sr} 2$ and pseudoblack chaff in wheat can be broken. Plant Breed. 124:520-522.

Moore, J. W., Herrera-Foessel, S., Caixia, L., Schnippenkoetter, W., Ayliffe, M., Huerta-Espino, J., Lillemo, M., Viccars, L., Milne, R., Periyannan, S., Kong, X., Spielmeyer, W., Talbot, M., Bariana, H., Patrick, J. W., Dodds, P., Singh, R., and Lagudah, E. S. 2015. A recently evolved hexose transporter variant confers resistance to multiple pathogens in wheat. Nat. Genet. 47: 1494-1498.

Rajaram, S., Singh, R. P., and Torres, E. 1988. Current CIMMYT approaches in breeding wheat for rust resistance. Pages 101-118 in: Breeding Strategies for Resistance to the Rust of Wheat. N. W. Simmonds and S. Rajaram, eds. CIMMYT, Mexico City, Mexico.

Sheen, S.-J., Ebeltoft, D. C., and Smith, G. S. 1968. Association and inheritance of "black chaff" and stem rust reactions in Conley wheat crosses. Crop Sci. 8:477-480.

Singh, R. P., Hodson, D. P., Huerta-Espino, J., Jin, Y., Bhavani, S., Njau, P., Herrera-Foessel, S., Singh, P. K., Singh, S. and Govindan, V. 2011a. The emergence of $\mathrm{Ug} 99$ races of the stem rust fungus is a threat to world wheat production. Annu. Rev. Phytopathol. 49:465-481.

Singh, R. P., Huerta-Espino, J., Bhavani, S., Herrera-Foessel, S. A., Singh, D., Singh, P. K., Velu, G., Mason, R. E., Jin, Y., Njau, P., and Crossa, J. 2011 b. Race non-specific resistance to rust diseases in CIMMYT spring wheats. Euphytica 179:175-186.

Singh, R. P., and McIntosh, R. A. 1984a. Complementary genes for reaction to Puccinia recondita tritici in Triticum aestivum I. Genetic and linkage studies. Can. J. Genet. Cytol. 26:723-735.

Singh, R. P., and McIntosh, R. A. 1984b. Complementary genes for reaction to Puccinia recondite tritici in Triticum aestivum II. Cytogenetic studies. Can. J. Genet. Cytol. 26:736-742.

Stakman, E., and Rodenhiser, H. 1959. Race 15B of wheat stem rust-What it is and what it means. Adv. Agron. 10:143-165.

Suenaga, K., Singh, R. P., Huerta-Espino, J., and William, H. M. 2003. Microsatellite markers for Lr34/Yr18 and other quantitative trait loci for leaf rust and stripe rust resistance in bread wheat. Phytopathology 93: 881-890.

Sunderwirth, S. D., and Roelfs, A. P. 1980. Greenhouse evaluation of the adult plant resistance of $S r 2$ to wheat stem rust. Phytopathology 70:634-637.

Yang, E. N., Rosewarne, G. M., Herrera-Foessel, S. A., Huerta-Espino, J., Tang, Z. X., Sun, C. F., Ren, Z. L., and Singh, R. P. 2013. QTL analysis of the spring wheat "Chapio" identifies stable stripe rust resistance despite intercontinental genotype $\times$ environment interactions. Theor. Appl. Genet. 126:1721-1732.

Yahiaoui, N., Srichumpa, P., Dudler, R., and Keller, B. 2004. Genome analysis at different ploidy levels allows cloning of the powdery mildew resistance gene Pm3b from hexaploid wheat. Plant J. 37:528-538.

Zadoks, J. C., Chang, T. T., and Konzak, C. F. 1974. A decimal code for the growth stages of cereals. Weed Res. 14:415-421.

Zhang, X., Dodds, P. N., and Bernoux, M. 2017. What do we know about NOD-like receptors in plant immunity? Annu. Rev. Phytopathol. 55: 205-229. 